\title{
CSResearch Square \\ TTK Predicts Triple Positive Breast Cancer Prognosis and Regulates Tumor Proliferation and
}

Invasion

\section{Yunhe Gao}

Jilin University Second Hospital

\section{Shanshan Qu}

Jilin University Second Hospital

\section{Lanqing Cao}

Jilin University Second Hospital

Min Yao ( $\nabla$ yaomin@jlu.edu.cn )

Jilin University Second Hospital

\section{Research}

Keywords: Overall survival, Disease-free survival, Prognosis, Cancer, Spindle assembly checkpoint

Posted Date: April 14th, 2021

DOI: https://doi.org/10.21203/rs.3.rs-407725/v1

License: (a) (i) This work is licensed under a Creative Commons Attribution 4.0 International License. Read Full License

Version of Record: A version of this preprint was published at Neoplasma on November 30th, 2021. See the published version at https://doi.org/10.4149/neo_2021_210421N541. 


\section{Abstract}

Background: This study was conducted to investigate the expression of the spindle assembly checkpoint kinase tyrosine/threonine kinase (TTK) in triple positive breast cancer (TPBC) and its effect on TPBC cells.

Methods: We analyzed the status of TTK in 69 TPBC samples using immunohistochemistry. The correlation between TTK and clinicopathological parameters was analyzed using a chi-squared test. The prognostic value of TTK was evaluated using Kaplan-Meier survival curves. We analyzed the role of TTK in the invasion and proliferation of TPBC cells in vitro and in vivo.

Results: The mean age of the 69 patients with TPBC enrolled in this study was 53 years (range: $29-86$ years). TTK expression was positively correlated with tumor size $(P=0.034)$, p53 status $(P=0.023)$, TNM stage $(P=0.023)$, and Ki-67 index $(P<0.001)$. The Kaplan-Meier curves revealed that TTK expression was correlated with poor disease-free survival $(P=0.001)$ and overall survival $(P=0.050)$. Multivariate proportional hazard regression analyses showed that TTK and TNM staging were significant independent predictors of disease-free survival ( $P=0.007$ and $P=0.034$, respectively). Additionally, TTK knockdown inhibited the invasion and proliferation of the BT474 TPBC cell line.

Conclusions: The findings of the study indicate that TTK overexpression is associated with cancer progression and prognosis in patients with TPBC, whereas TTK knockdown inhibits the invasion and proliferation of TPBC cells. Thus, TTK may serve as a prognostic marker for TPBC.

\section{Background}

Understanding breast cancer biology is important in terms of both therapy management and assessment of patient outcomes. Breast cancer has been classified into different subtypes based on the expression of estrogen receptors (ERs), progesterone receptors, and human epidermal growth factor receptor 2 (HER2). Recently, a distinct subcategory of HER2-enrichedbreast cancer with positive hormone receptors has been identified (HER2-positive breast cancer). This subtype exhibits high levels of hormone receptor expression and is referred to as "triple positive" breast cancer (TPBC). In ER + luminal tumors, preclinical evidence suggests that strong crosstalk occurs between the ER and HER2 signaling pathways and that activation of the ER pathway leads to resistance to anti-HER2 therapy; furthermore, from a genomic/transcriptomic perspective, ER+/HER2 + tumors may be much more common than ER-/HER2 + tumors and have fewer tumor-infiltrating lymphocytes and lower PD-L1 expression [1, 2]. Current treatment guidelines, however, do not propose distinct management strategies for ER+/HER2 + and ER-/HER2 + breast cancer[3, 4]. TPBC responds distinctly to conventional treatment [5]. This raises the question of whether it is necessary to tailor TPBC therapy to individuals.

The spindle assembly checkpoint is a signaling cascade that prevents chromosome missegregation by arresting mitosis until all chromosomes are properly attached to the mitotic spindle[6]. As the core spindle assembly checkpoint kinase, tyrosine/threonine kinase (TTK) is a dual-specificity kinase that can 
phosphorylate serine/threonine and tyrosine residues [7]. TTK is critical for the recruitment of spindle assembly checkpoint proteins to unattached kinetochores, mitotic checkpoint complex formation, and mitotic arrest [8]. Inhibition of TTK activity causes cells to prematurely exit mitosis with unattached chromosomes, resulting in severe chromosome missegregation, aneuploidy, and eventually cell death [912]. Overexpression of mitotic checkpoint genes leads to chromosomal instability in cancer cells [13-16].

Previous studies have shown that TTK is overexpressed in breast cancer cells, particularly in the HER2 + and triple negative breast cancer (TNBC) subtypes[13,14,17, 18]. However, whether TTK is also a prognostic factor in TPBC remains unclear. In this study, we analyzed the expression of TTK in TPBC and further analyzed the biological function of TTK in the progression of TPBC.

\section{Methods}

\section{TPBC tissue and cell line}

We retrospectively collected data and tissue specimens from 69 patients with TPBC who had undergone tumor surgical resection at the Second Hospital of Jilin University between January 2009 and January 2013. Patients administered preoperative neoadjuvant chemotherapy or hormonal treatment were excluded from this study. The 69 patients had been diagnosed with invasive carcinoma of no special type. The last follow-up was conducted in April 2018 (mean follow-up duration: 44.2 months, range: 1.67-72.10 months).

Clinicopathological data were retrieved from patient medical records. These parameters included patient age at initial diagnosis, histological subtype, tumor size, lymph node metastasis, and clinical outcome. The study protocol was approved by the Institutional Ethics Committee of the Second Hospital of Jilin University, Jilin, China (IRB approval number: 2020008). The need for written informed consent was waived because of the retrospective nature of the study.

Two-micrometer-thick sections were prepared from paraffin blocks of breast cancer tissues retrieved from the Pathology Department, Second Hospital of Jilin University, for immunohistochemistry and hematoxylin and eosin staining. The latter was used to confirm the diagnoses, and the results were reviewed by Min Yao and Yunhe Gao. Tumor histological grades were assessed using the Nottingham grading system [19].

A human breast carcinoma cell line, BT474, which is a TPBC cell line, was purchased from the American Type Culture Collection (Manassas, VA, USA). The cell line was maintained in RPMI-1640 supplemented with $10 \%$ fetal bovine serum at $37^{\circ} \mathrm{C}$ in a humidified atmosphere with $5 \% \mathrm{CO}_{2}$.

\section{Immunohistochemistry}

Immunohistochemical staining was performed automatically using the PT Link Pre-Treatment system and Autostainer Link 48 system (both from DAKO, Carpinteria, CA, USA). Endogenous peroxidases were 
quenched with $3 \% \mathrm{H}_{2} \mathrm{O}_{2}$ for 10 min. The sections were incubated with primary antibodies against TTK (Cat. \#AF6028; NOVUS, St. Louis, MI, USA; 1:200 dilution in phosphate-buffered saline [PBS]) and AKT (Cat. \#4691) and Ki-67 (Cat. \#9449) from Cell Signaling Technology (Danvers, MA, USA) at 1:300 dilution in PBS for $30 \mathrm{~min}$, followed by the secondary biotinylated antibody for $20 \mathrm{~min}$. The slides were stained using 3, 3'-diaminobenzidine and counterstained with hematoxylin.

\section{Review and scoring of immunostained tissue sections}

The immunostained tissue sections were independently reviewed and scored by two investigators to determine the immunostaining percentage and staining intensity, as described previously [20]. A numerical final expression score (FS) was calculated for each tissue sample by multiplying the staining intensity (I) score ( 0 , negative; 1 , weak; 2 , moderate; 3 , strong staining) by the percentage $(P)$ of positively stained cells $(F S=P \times I)$. Final expression score, therefore, ranged from 0 to 300 . Thereafter, each case was scored as positive or negative using the median final expression score as the cutoff value for statistical analysis [21].

\section{Cell proliferation and colony formation experiments}

Cells were seeded into 96 -well plates at a density of $5.0 \times 10^{3}$ cells per well and cultured for $24 \mathrm{~h}$. The cells were then incubated with $10 \mu \mathrm{L}$ of CCK-8 (Beyotime Biotechnology LLC, Shanghai, China) solution for $30-45 \mathrm{~min}$ at $37^{\circ} \mathrm{C}$. Absorbance at $450 \mathrm{~nm}$ was detected with a microplate reader (Model 680; BioRad, Hercules, CA, USA $)$. The cell inhibitory index was calculated as [1-( $\mathrm{A} 45 \mathrm{~s}_{\text {sample }}{ }^{-}$

$\left.\left.\mathrm{A} 450_{\text {blank }}\right) /\left(\mathrm{A} 450_{\text {control }}-\mathrm{A} 450_{\text {blank }}\right)\right] \times 100 \%$. The transfected cells were seeded into a culture plate at 200 cells/well, and after 2 weeks of incubation, the cells were washed with PBS and stained with Giemsa solution. The number of colonies containing $>50$ cells was counted under a microscope.

\section{Western blot analysis}

Cells were lysed using RIPA buffer (Beyotime Biotechnology), vortexed for $30 \mathrm{~s}$, and centrifuged at 14000 $\times g$ for $5 \mathrm{~min}$. The supernatants were collected and stored at $-20^{\circ} \mathrm{C}$. The whole-cell lysates were resolved by SDS-PAGE, and the proteins were blotted onto a nitrocellulose membrane. The expression of various proteins was detected using primary antibodies against the following: TTK (Cat. \#AF6028; NOVUS; 1:500 dilution in PBS); AKT (Cat. \#4691), CCND1 (Cat. \#55506), CCND2 (Cat. \#3741), CDK4 (Cat. \#12790), CDK6 (Cat. \#13331), p21 (Cat. \#2947), E-cadherin (Cat. \#14472), N-cadherin (Cat. \#13116), vimentin (Cat. \#5741), and Snail (Cat. \#3879) from Cell Signaling Technology at 1:1000 dilution in PBS, and $\beta$-actin (Cat. \#HC201-01; TransGen Biotechnology LLC, Beijing, China; 1:1000 dilution in PBS). The corresponding secondary antibodies were anti-mouse and anti-rabbit antibodies. Immunoreactive bands were visualized via enhanced chemiluminescence.

\section{The 5-ethynyl-2'-deoxyuridine (EdU) proliferation assay}

To demonstrate the effect of TTK on the proliferation of BT474 cells, an EdU proliferation assay was performed according to the manufacturer's instructions. The cells were incubated with $50 \mu \mathrm{M} \mathrm{EdU}$ for $2 \mathrm{~h}$ and stained with Ado-Lo and 4',6-diamidino-2-phenylindole (DAPI). The number of EdU-positive cells was 
detected via fluorescence microscopy. The display rate of EdU-positive cells was calculated as the ratio of the number of EdU-positive cells to the total number of DAPI-stained cells (blue cells).

\section{Cell transfection}

A TTK-targeting short hairpin RNA (shRNA) plasmid, pLVshRNA-EGFP(2A)Puro-TTK-shRNA1 (\#P11886; MiaoLingBio, Changchun, China), which also expressed green fluorescent protein, was constructed and transfected into BT474cells. A functional, nontargeting shRNA, and an empty vector were used as controls.

\section{Quantitative reverse transcription-PCR (qRT-PCR)}

Total RNA was isolated from $5 \times 10^{6}$ cells by using TRIzol reagent (Invitrogen, Carlsbad, CA, USA) according to the manufacturer's instructions. Total RNA concentration and purity were analyzed in duplicate samples by using a NanoDropND-2000 spectrophotometer (Thermo Fisher Scientific, Waltham, MA, USA). cDNA was synthesized from qualified RNA by using an RT-PCR reverse transcription kit (TransGen Biotechnology LLC), and $1 \mu \mathrm{g}$ of total RNA was reverse-transcribed into cDNA under the following conditions: $25^{\circ} \mathrm{C}$ for $10 \mathrm{~min}, 42^{\circ} \mathrm{C}$ for $30 \mathrm{~min}$, and $85^{\circ} \mathrm{C}$ for $5 \mathrm{~s}$, as per the manufacturer's recommendations. The $\mathrm{CDNA}$ was stored at $-20^{\circ} \mathrm{C}$ until use. PCR was performed using a PCR kit (TransGen Biotechnology LLC), and the PCR products were electrophoresed on 1.5\% agarose gels. qPCR was conducted with either Taq-Man or SYBR Green PCR reagents on an ABI Prism 7300 detection system (all from Applied Biosystems, Foster City, CA, USA). The reaction program was as follows: $95^{\circ} \mathrm{C}$ for 3 min, followed by 40 cycles at $95^{\circ} \mathrm{C}$ for $30 \mathrm{~s}$ and $55^{\circ} \mathrm{C}$ for $20 \mathrm{~s}$, and $72^{\circ} \mathrm{C}$ for $15 \mathrm{~s}$. GAPDH served as an internal control, and relative mRNA levels were calculated using the $2^{-\Delta \Delta C t}$ method[22]. The following primers were synthesized by Sangon Biotech (Shanghai, China):

TTK, (qRT-PCR)-forward: TCCCCAGCGCAGCTTTCTGTAGA;

TTK, (qRT-PCR)-reverse: CCAGTCCTCTGGGTTGTTTGCCAT;

GAPDH, (qRT-PCR)-forward: GGAGCGAGATCCCTCCAAAAT;

GAPDH, (qRT-PCR) -reverse: GGCTGTTGTCATACTTCTCATGG.

\section{Transwell invasion assay}

The transfected cells were inoculated into the upper chamber of a Transwell chamber (Corning, Inc., Corning, NY, USA) at $1 \times 10^{5}$ cells $/ \mathrm{mL}$, and RPMI- 1640 medium supplemented with $30 \%$ fetal bovine serum was added to the lower chamber. The cells were cultured in $5 \% \mathrm{CO}_{2}$ and $100 \%$ humidity and at $37^{\circ} \mathrm{C}$ constant temperature for $24 \mathrm{~h}$. The chamber was removed, and the cells were rinsed with PBS and fixed in absolute ethanol for $40 \mathrm{~min}$. After crystal violet staining, the cells that did not pass through the upper chamber were wiped off using a cotton swab, and cells that had passed through the upper chamber were counted under an inverted microscope. Finally, invasive cells on the lower surface of the membrane were 
counted using a microscope. Five fields of view were randomly selected to detect changes in invasion ability. The experiment was repeated three times.

\section{Animal studies}

Fourteen female BALB/c nude mice (6 weeks old) were purchased from SPF Biotechnology (Beijing, China) and randomized into two groups. All animal experiments were conducted in accordance with the institutional guidelines and approved by the Experimental Animal Ethical Committee of Jilin University. Cells were injected subcutaneously into the right buttock of each mouse at $1 \times 10^{6}$ cells per $0.1 \mathrm{~mL}$ PBS. All mice were maintained in a standardized barrier system environment at the Animal Experiment Center of the Basic Medical College of Jilin. After 4 weeks of observation, the mice were euthanized. The xenograft tumors were removed and fixed in 10\% formalin. The tumors were measured using a Vernier caliper, and the volume was calculated using the following formula: $V=\left(\right.$ width $^{2} \times$ length)/2[23]. The xenograft tumors were examined macroscopically and subjected to hematoxylin and eosin staining and immunohistochemistry.

\section{Statistical analyses}

All statistical analyses were performed using SPSS v. 21.0 (SPSS, Inc, Chicago, IL, USA). Continuous variables were evaluated using the Mann-Whitney U test, whereas categorical variables were analyzed with the chi-squared test. Furthermore, significant variables $(P<0.05)$ from the univariate analyses were included in multivariate analyses. A multivariate Cox proportional hazards model was used to obtain hazard ratios for survival and to identify factors affecting disease-free survival (DFS) and overall survival (OS). Kaplan-Meier survival curves and log-rank tests were used to evaluate DFS and OS. Experiments were repeated at least three times. $P<0.05$ was considered to indicate statistically significant differences.

\section{Results}

\section{Patient characteristics}

The median age of the69 patients with invasive breast cancer included in this study was 53 years (range: 29-86 years). According to the seventh edition of the UICC cancer staging system grouping criteria, 17.4\% (12/69), 43.5\% (30/69), and 39.1\% (27/69) of the TPBC patients had stage I, II, and III disease, respectively. All patients exhibited invasive breast ductal carcinoma and underwent modified radical mastectomy. Among the patients with available adjuvant treatment information, 97.1\% (67/69) were administered chemotherapy (two ceased treatment because of an allergic reaction) and 33.3\% (23/69) were treated with radiation.
Associations between TTK expression and clinicopathological parameters in patients with breast cancer 
The associations between TTK expression and clinicopathological parameters were analyzed using Pearson's chi-squared test (Table 1). TTK positivity was observed in $39.1 \%(27 / 69)$ of TPBC tissues (Fig. 1a). TTK expression was positively associated with tumor size $(P=0.034)$, p53 mutation $(P=0.023)$, TNM stage $(P=0.023)$, and Ki-67 expression $(P<0.001)$. The larger tumor size and higher Ki-67 expression under TTK overexpression suggest that TPBC is more proliferative and has higher vitality than TTK-negative TPBC. Furthermore, the p53 mutation and advanced TNM stages associated with TTK overexpression indicate that TPBC has more aggressive clinicopathological features than other forms of breast cancer. 
Table 1

Association of TTK expression with clinicopathological parameters of patients with TPBC

\begin{tabular}{|c|c|c|c|c|c|}
\hline \multirow[t]{2}{*}{ Characteristics } & & \multirow[t]{2}{*}{ No. } & \multicolumn{2}{|l|}{ TTK expression } & \multirow[t]{2}{*}{$P$ value } \\
\hline & & & Negative No. (\%) & Positive No. (\%) & \\
\hline \multirow[t]{2}{*}{ Age (years) } & $<50$ & 18 & 12 & 6 & \multirow[t]{2}{*}{0.558} \\
\hline & $\geq 50$ & 51 & 30 & 21 & \\
\hline \multirow[t]{3}{*}{ Size (cm) } & $\leq 2$ & 30 & 21 & 9 & \multirow[t]{3}{*}{0.034} \\
\hline & $2-5$ & 30 & 19 & 11 & \\
\hline & $>5$ & 9 & 2 & 7 & \\
\hline \multirow[t]{3}{*}{ Histology grade } & 1 & 3 & 3 & 0 & \multirow[t]{3}{*}{0.121} \\
\hline & 2 & 63 & 36 & 27 & \\
\hline & 3 & 3 & 3 & 0 & \\
\hline \multirow[t]{4}{*}{ Lymph node status } & Negative & 24 & 14 & 10 & \multirow[t]{4}{*}{0.715} \\
\hline & $1-3$ & 18 & 10 & 8 & \\
\hline & $4-9$ & 12 & 6 & 6 & \\
\hline & $>9$ & 15 & 6 & 9 & \\
\hline \multirow[t]{3}{*}{ TNM stage } & 1 & 12 & 9 & 3 & \multirow[t]{3}{*}{0.023} \\
\hline & $\|$ & 30 & 22 & 8 & \\
\hline & III & 27 & 11 & 16 & \\
\hline \multirow[t]{2}{*}{ P53 status } & wild-type & 49 & 34 & 15 & \multirow[t]{2}{*}{0.023} \\
\hline & mutant-type & 20 & 8 & 12 & \\
\hline \multirow[t]{2}{*}{ BCL-2 status } & Negative & 12 & 9 & 3 & \multirow[t]{2}{*}{0.270} \\
\hline & Positive & 57 & 33 & 24 & \\
\hline \multirow[t]{2}{*}{ Ki-67 status } & $\leq 20 \%$ & 30 & 27 & 3 & \multirow[t]{2}{*}{$<0.001$} \\
\hline & $>20 \%$ & 39 & 15 & 24 & \\
\hline
\end{tabular}

\section{Association between TTK expression and patient survival}

Kaplan-Meier curves and a log-rank test were used to analyze OS and DFS after stratification by TTK expression. TTK expression was significantly correlated with DFS $(P=0.001$, Fig. $1 \mathrm{~b})$ and OS $(P=0.050$, 
Fig. 1b).

We further investigated the prognostic value of various clinicopathological parameters using KaplanMeier curves and a log-rank test (Table 2). This revealed a significant association between DFS and tumor size $(P=0.020)$, p53 mutation $(P=0.005)$, TTK status $(P=0.001)$, and TNM stage $(P<0.001)$. OS was significantly associated with tumor size $(P=0.044)$, BCL-2 status $(P=0.001)$, p53 mutation $(P<$ $0.001)$, Ki67 index $(P=0.014)$, TTK status $(P=0.050)$, and TNM stage $(P=0.038)$. Significant parameters were selected for multivariate analysis (Table 3$)$. In the multivariate Cox regression model, TTK and TNM staging were identified as significant independent predictors of DFS $(P=0.007$ and $P=0.034$, respectively) among all patients with TPBC (Table 3). TTK expression was significantly higher in TPBC tissues than in normal breast tissues, according to western blot analysis (Fig. 1c).

Table 2

Univariate analyses of disease-free survival and overall survival for patients with TPBC

\begin{tabular}{|lllll|}
\hline & DFS & \multicolumn{3}{l|}{ OS } \\
\hline & Log rank & P value & Log rank & P value \\
\hline Histology grade(II/ III vs. I) & 1.667 & 0.435 & 1.955 & 0.376 \\
\hline Age (<50 vs. $\geq 50)$ & 0.019 & 0.890 & 0.042 & 0.838 \\
\hline Tumor size (2-5cm/>5. cm vs. 2cm) & 7.817 & 0.020 & 6.228 & $\mathbf{0 . 0 4 4}$ \\
\hline Lymph node status (Present vs. Absent) & 4.883 & 0.181 & 4.419 & 0.220 \\
\hline BCL-2 (Positive vs. Negative) & 2.004 & 0.157 & 10.667 & $\mathbf{0 . 0 0 1}$ \\
\hline P53 (mutant vs. wild) & 7.96 & 0.005 & 13.636 & $<\mathbf{0 . 0 0 1}$ \\
\hline Ki-67 (> 20\% vs. $\leq 20 \%)$ & 2.009 & 0.147 & 6.000 & $\mathbf{0 . 0 1 4}$ \\
\hline TTK(Positive vs. Negative) & 10.490 & $\mathbf{0 . 0 0 1}$ & 5.997 & $\mathbf{0 . 0 5 0}$ \\
\hline TNM (II/ III vs. I) & 25.737 & $<0.001$ & 4.316 & $\mathbf{0 . 0 3 8}$ \\
\hline TNM: Tumor Node Metastasis; TTK: tyrosine/threonine kinase. & & \\
\hline
\end{tabular}


Table 3

Multivariate analyses of disease-free survival and overall survival for patients with TPBC

\begin{tabular}{|c|c|c|c|c|c|c|}
\hline & DFS & & & os & & \\
\hline & HR & $95 \% \mathrm{Cl}$ & $\begin{array}{l}P \\
\text { value }\end{array}$ & HR & $95 \% \mathrm{Cl}$ & $\begin{array}{l}P \\
\text { value }\end{array}$ \\
\hline Histology grade(II/ III vs. I) & NA & NA & NA & NA & NA & NA \\
\hline Age (<50 vs. $\geq 50)$ & NA & NA & NA & NA & NA & NA \\
\hline $\begin{array}{l}\text { Tumor size }(2-5 \mathrm{~cm} />5 \mathrm{~cm} \\
\text { vs. } 2 \mathrm{~cm})\end{array}$ & 0.598 & $\begin{array}{l}0.499- \\
3.399\end{array}$ & 0.598 & 1.519 & $0.572-4.034$ & 0.401 \\
\hline $\begin{array}{l}\text { Lymph node status (Present } \\
\text { vs. Absent) }\end{array}$ & 1.012 & $\begin{array}{l}0.641- \\
1.598\end{array}$ & 0.96 & 2.509 & $0.304-1.44$ & 0.298 \\
\hline $\begin{array}{l}\text { BCL-2 (Positive vs. } \\
\text { Negative) }\end{array}$ & NA & NA & NA & 0.984 & $0.195-4.957$ & 0.984 \\
\hline P53 (mutant vs. wild) & 2.27 & $\begin{array}{l}0.911- \\
5.661\end{array}$ & 0.079 & 45.164 & $\begin{array}{l}0.144- \\
141.490\end{array}$ & 0.194 \\
\hline Ki-67 (> 20\% vs. $\leq 20 \%$ ) & 0.928 & $\begin{array}{l}0.517- \\
1.664\end{array}$ & 0.801 & 1.341 & $0.315-1.570$ & 0.745 \\
\hline TTK (Positive vs. Negative) & 3.736 & $\begin{array}{l}1.439- \\
9.696\end{array}$ & 0.007 & 0.984 & $0.195-4.957$ & 0.985 \\
\hline TNM (II/ III vs. I) & 2.337 & $\begin{array}{l}1.042- \\
4.769\end{array}$ & 0.034 & 2.179 & $0.436-11.076$ & 0.322 \\
\hline
\end{tabular}

\section{TTK knockdown inhibits TPBC cell proliferation}

To investigate the potential role of TTK in TPBC cells, we designed and tested TTK-targeting shRNAs and identified two shRNAs that effectively knocked down TTK expression in BT474 cells (Figs. 2a and 2b). The CCK-8 assay showed that the survival rate of BT474 cells was significantly reduced after TTK knockdown (shTTK group vs. control group, $P<0.001$; Fig. 3a). Furthermore, colony formation ability experiments and an EdU assay were performed to mimic the ability of cells to form multicellular clones from individual tumor cells (Figs. $3 b$ and $3 c$ ). The number of BT474 cells in the shTTK group was remarkably lower than that in the control group $(P<0.05$ and $P<0.05)$. Furthermore, in the shTTK group, CCND1, CCND2, CDK4, CDK6, and p21 expression levels were significantly lower than those in the control group (Fig. 3d). These findings suggest that downregulation of TTK can significantly inhibit proliferation of the BT474 TPBC cell line and reduce colony formation. After transfection with TTK-targeting shRNA, AKT expression was significantly lower in BT474 cells than in control cells (Fig. 3d).

\section{TTK knockdown inhibits invasiveness of TPBC cells}


Epithelial-mesenchymal transition (EMT), an invasive phenotype of cancer cells, plays a key role in tumor metastasis. Western blot analysis revealed that the expression of EMT proteins (E-cadherin, vimentin, $\mathrm{N}$-cadherin, and Snail) was significantly altered by TTK knockdown. The expression of Ecadherin was significantly higher, and that of vimentin, N-cadherin, and Snail protein was significantly lower, in the shTTK group than in the control group (Fig. 4a). The Transwell assay revealed the effects of $T T K$ knockdown on the invasiveness ofBT474 cells. There were significantly fewer invading cells in the shTTK group than in the control group ( $P=0.005)$ (Fig. 4b). These results suggest that TTK enhances the invasiveness of BT474 cells by regulating EMT.

\section{TTK knockdown inhibits tumor growth in a breast cancer xenograft model}

TTK suppression was examined in nude mice bearing established control and shTTK BT474 xenograft tumors. TTK suppression inhibited tumor growth in the shTTK group compared to that in the control group in this xenograft model (Fig. 5a). Moreover, based on the tumor tissue immunohistochemistry results, TTK, AKT, and Ki-67 expression was suppressed in the shTTK group relative to that in the control group (Figs. $5 \mathrm{~b}$ and5c); this is consistent with the in vitro results. These results indicate that TTK enhanced tumor growth in vivo, possibly via the AKT pathway.

\section{Discussion}

In this study, we found that TTK expression enhanced the proliferation and metastasis of BT474 TPBC cells. Furthermore, unlike in TNBC, TTK overexpression was associated with worse prognosis in patients with TPBC. Encouraging results have been obtained using a dual blockade strategy comprising anti-HER2 agents and hormonal therapy [24]. Patients with the HER2-enriched molecular subtype of breast cancer and those at high risk of relapse are typically administered adjuvant trastuzumab as the anti-HER2 agent, along with chemotherapy and endocrine therapy.

Consistent with our results, AI-Ejeh et al. [17] revealed that TTK protein levels were elevated in aggressive tumors, leading to poor survival. Most previous TNBC studies focused on aberrant TTK expression in TNBCs, an event that is significantly associated with an elevated risk of relapse and docetaxel resistance $[17,18,25,26]$. Based on these findings, we hypothesized that aberrant TTK expression facilitates the progression of TPBC. Accordingly, we found that TTK expression was significantly higher in TPBCs with a poor prognosis than in those with a good prognosis. Assessing TTK expression augments the prognostic information provided by the traditional prognostic indicators ER, progesterone receptor, and HER2. This is the first study to evaluate the effect of TTK expression on the survival of a consecutive TPBC cohort.

To further investigate the functional role of TTK in the progression of TPBC, we used a lentivirus to achieve TTK knockdown in BT474 cells. TTK knockdown inhibited the proliferation, colony formation, and invasiveness of TPBC cells, both in vivo and in vitro. Additionally, TTK knockdown may affect the 
expression of proteins associated with proliferation and invasiveness. Recent research has indicated that TTK promotes cell migration and EMT by enhancing the expression of dihydropyrimidinase-like 3 (DPYSL3), thus promoting snail-regulated EMT, and reinforcing the metastatic potential and ultimately tumor metastasis in TPBC. TTK and DPYSL3 upregulation was negatively correlated with clinical outcome in patients with lung cancer [27]. Importantly, our findings revealed that TTK protein expression was positively correlated with tumor size, TNM stage, p53 mutation status, and the Ki-67 index. Consistent with our findings, previous studies have shown that TTK is expressed significantly more in breast cancers expressing mutant p53 than in those expressing wild-type p53, independent of the breast cancer subtype [28]. In patients with breast cancer, TTK overexpression is associated with increased breast cancer grade and aggressiveness, possibly because it promotes the proliferation or survival of cancer cells [25].

The AKT signaling pathway can exert proliferative effects by targeting downstream transcription factors. TTK promotes cell proliferation and invasiveness by activating the AKT/mTOR and MDM2/p53 signaling pathways [29]. Our findings demonstrate that reducing TTK expression can inhibit the activation of AKT expression and proliferation of breast cancer cells. Many clinical trials[9-11, 13, 30-32] have assessed the effects of TTK inhibitors in TNBC treatment and showed that TTK inhibitors may be effective as second-line therapy for TPBC, particularly for resistant patients; our findings are consistent with these results. Additional large cohort studies are required to validate the positive effects of anti-TTK therapy.

In conclusion, TTK upregulation was closely associated with TPBC progression and poor prognosis. Thus, TTK may serve as a valuable prognostic marker and therapeutic target for TPBC.

\section{Abbreviations}

DFS: disease-free survival; EdU: 5'-ethynyl-2'-deoxyuridine; ER: estrogen receptor; HER2: human epidermal growth factor receptor 2; OS: overall survival; qRT-PCR: quantitative reverse transcription polymerase chain reaction; shRNA: short hairpin RNA; TPBC: triple positive breast cancer; TTK: tyrosine/threonine kinase; TNBC, triple negative breast cancer

\section{Declarations}

\section{Ethics approval and consent to participate}

The study protocol was approved by the Institutional Ethics Committee of the Second Hospital of Jilin University, Jilin, China (IRB approval number: 2020008). The need for written informed consent was waived because of the retrospective nature of the study.

\section{Consent for publication}

Not applicable 
Availability of data and materials

The datasets used and/or analyzed during the current study are available from the corresponding author on reasonable request.

\section{Conflict of interests}

The authors declare that the research was conducted in the absence of any commercial or financial relationships that could be construed as a potential conflict of interest.

\section{Funding}

This study was supported in part by grants from the Science and Technology Development Project of Jilin Province (grant no. 3D5197431429).

\section{Acknowledgments}

The authors would like to thank Dr. Yantong Guo for providing technical assistance.

\section{Author contributions}

All authors contributed to the study conception and design; data acquisition, analysis, and interpretation; manuscript drafting and manuscript revision for important intellectual content; and clinical studies. Additionally, all authors approved final version of submitted manuscript and are responsible for ensuring that questions related to the work are appropriately resolved. YG and MY conducted the literature research, statistical analyses, and manuscript editing, and are the guarantors of integrity of the entire study.

\section{References}

1. Barroso-Sousa R, Barry WT, Guo H, Dillon D, Tan YB, Fuhrman K, Osmani W, Getz A, Baltay M, Dang C, et al. The immune profile of small HER2-positive breast cancers: a secondary analysis from the APT trial. Ann Oncol. 2019;30:575-81.

2. Llombart-Cussac A, Cortes J, Pare L, Galvan P, Bermejo B, Martinez N, Vidal M, Pernas S, Lopez R, Munoz M, et al. HER2-enriched subtype as a predictor of pathological complete response following trastuzumab and lapatinib without chemotherapy in early-stage HER2-positive breast cancer (PAMELA): an open-label, single-group, multicentre, phase 2 trial. Lancet Oncol. 2017;18:545-54.

3. Giordano SH, Temin S, Kirshner JJ, Chandarlapaty S, Crews JR, Davidson NE, Esteva FJ, GonzalezAngulo AM, Krop I, Levinson J, et al. Systemic therapy for patients with advanced human epidermal growth factor receptor 2-positive breast cancer: American Society of Clinical Oncology clinical practice guideline. J Clin Oncol. 2014;32:2078-99.

4. Cardoso F, Costa A, Senkus E, Aapro M, Andre F, Barrios CH, Bergh J, Bhattacharyya G, Biganzoli L, Cardoso MJ, et al. 3rd ESO-ESMO International Consensus Guidelines for Advanced Breast Cancer 
(ABC 3). Ann Oncol. 2017;28:3111.

5. Vici P, Pizzuti L, Natoli C, Gamucci T, Di Lauro L, Barba M, Sergi D, Botti C, Michelotti A, Moscetti L, et al. Triple positive breast cancer: a distinct subtype? Cancer Treat Rev. 2015;41:69-76.

6. Lara-Gonzalez P, Westhorpe FG, Taylor SS. The spindle assembly checkpoint. Curr Biol. 2012;22:R966-80.

7. Lauze E, Stoelcker B, Luca FC, Weiss E, Schutz AR, Winey M. Yeast spindle pole body duplication gene MPS1 encodes an essential dual specificity protein kinase. Embo j. 1995;14:1655-63.

8. Xu Q, Zhu S, Wang W, Zhang X, Old W, Ahn N, Liu X. Regulation of kinetochore recruitment of two essential mitotic spindle checkpoint proteins by Mps1 phosphorylation. Mol Biol Cell. 2009;20:1020.

9. Hewitt L, Tighe A, Santaguida S, White AM, Jones CD, Musacchio A, Green S, Taylor SS. Sustained Mps1 activity is required in mitosis to recruit O-Mad2 to the Mad1-C-Mad2 core complex. J Cell Biol. 2010;190:25-34.

10. Jemaa M, Galluzzi L, Kepp O, Senovilla L, Brands M, Boemer U, Koppitz M, Lienau P, Prechtl S, Schulze $V$, et al. Characterization of novel MPS1 inhibitors with preclinical anticancer activity. Cell Death Differ. 2013;20:1532-45.

11. Kwiatkowski N, Jelluma N, Filippakopoulos P, Soundararajan M, Manak MS, Kwon M, Choi HG, Sim T, Deveraux QL, Rottmann S, et al. Small-molecule kinase inhibitors provide insight into Mps1 cell cycle function. Nat Chem Biol. 2010;6:359-68.

12. Colombo R, Caldarelli M, Mennecozzi M, Giorgini ML, Sola F, Cappella P, Perrera C, Depaolini SR, Rusconi L, Cucchi U, et al. Targeting the mitotic checkpoint for cancer therapy with NMS-P715, an inhibitor of MPS1 kinase. Cancer Res. 2010;70:10255-64.

13. Daniel J, Coulter J, Woo JH, Wilsbach K, Gabrielson E. High levels of the Mps1 checkpoint protein are protective of aneuploidy in breast cancer cells. Proc Natl Acad Sci U S A. 2011;108:5384-9.

14. Yuan B, Xu Y, Woo JH, Wang Y, Bae YK, Yoon DS, Wersto RP, Tully E, Wilsbach K, Gabrielson E. Increased expression of mitotic checkpoint genes in breast cancer cells with chromosomal instability. Clin Cancer Res. 2006;12:405-10.

15. Salvatore G, Nappi TC, Salerno P, Jiang Y, Garbi C, Ugolini C, Miccoli P, Basolo F, Castellone MD, Cirafici AM, et al. A cell proliferation and chromosomal instability signature in anaplastic thyroid carcinoma. Cancer Res. 2007;67:10148-58.

16. Ling Y, Zhang X, Bai Y, Li P, Wei C, Song T, Zheng Z, Guan K, Zhang Y, Zhang B, et al. Overexpression of Mps1 in colon cancer cells attenuates the spindle assembly checkpoint and increases aneuploidy. Biochem Biophys Res Commun. 2014;450:1690-5.

17. Al-Ejeh F, Simpson PT, Saunus JM, Klein K, Kalimutho M, Shi W, Miranda M, Kutasovic J, Raghavendra A, Madore J, et al. Meta-analysis of the global gene expression profile of triple-negative breast cancer identifies genes for the prognostication and treatment of aggressive breast cancer. Oncogenesis. 2014;3:e124. 
18. Maire V, Baldeyron C, Richardson M, Tesson B, Vincent-Salomon A, Gravier E, Marty-Prouvost B, De Koning L, Rigaill G, Dumont A, et al. TTK/hMPS1 is an attractive therapeutic target for triple-negative breast cancer. PLoS One. 2013;8:e63712.

19. Elston CW, Ellis IO. Pathological prognostic factors in breast cancer. I. The value of histological grade in breast cancer: experience from a large study with long-term follow-up. Histopathology. 1991;19:403-10.

20. Won KY, Kim GY, Kim YW, Song JY, Lim SJ. Clinicopathologic correlation of beclin-1 and bcl-2 expression in human breast cancer. Hum Pathol. 2010;41:107-12.

21. Cao L, Sun PL, Yao M, Jia M, Gao H. Expression of YES-associated protein (YAP) and its clinical significance in breast cancer tissues. Hum Pathol. 2017;68:166-74.

22. Livak KJ, Schmittgen TD. Analysis of relative gene expression data using real-time quantitative PCR and the 2(-Delta Delta C(T)) Method. Methods. 2001;25:402-8.

23. Naito S, von Eschenbach AC, Giavazzi R, Fidler IJ. Growth and metastasis of tumor cells isolated from a human renal cell carcinoma implanted into different organs of nude mice. Cancer Res. 1986;46:4109-15.

24. Kaufman B, Mackey JR, Clemens MR, Bapsy PP, Vaid A, Wardley A, Tjulandin S, Jahn M, Lehle M, Feyereislova A, et al. Trastuzumab plus anastrozole versus anastrozole alone for the treatment of postmenopausal women with human epidermal growth factor receptor 2-positive, hormone receptorpositive metastatic breast cancer: results from the randomized phase III TAnDEM study. J Clin Oncol. 2009;27:5529-37.

25. Maia AR, de Man J, Boon U, Janssen A, Song JY, Omerzu M, Sterrenburg JG, Prinsen MB, WillemsenSeegers N, de Roos JA, et al. Inhibition of the spindle assembly checkpoint kinase TTK enhances the efficacy of docetaxel in a triple-negative breast cancer model. Ann Oncol. 2015;26:2180-92.

26. Gyorffy B, Bottai G, Lehmann-Che J, Keri G, Orfi L, Iwamoto T, Desmedt C, Bianchini G, Turner NC, de The $\mathrm{H}$, et al. TP53 mutation-correlated genes predict the risk of tumor relapse and identify MPS1 as a potential therapeutic kinase in TP53-mutated breast cancers. Mol Oncol. 2014;8:508-19.

27. Tsai YM, Wu KL, Chang YY, Hung JY, Chang WA, Chang CY, Jian SF, Tsai PH, Huang YC, Chong IW. Upregulation of Thr/Tyr kinase Increases the Cancer Progression by Neurotensin and Dihydropyrimidinase-Like 3 in Lung Cancer. 2020, 21.

28. Morrison CD, Chang JC, Keri RA, Schiemann WP. Mutant p53 dictates the oncogenic activity of c-Abl in triple-negative breast cancers. Cell Death Dis. 2017;8:e2899.

29. Liu X, Liao W, Yuan Q, Ou Y, Huang J. TTK activates Akt and promotes proliferation and migration of hepatocellular carcinoma cells. Oncotarget. 2015;6:34309-20.

30. Tardif KD, Rogers A, Cassiano J, Roth BL, Cimbora DM, McKinnon R, Peterson A, Douce TB, Robinson $\mathrm{R}$, Dorweiler I, et al. Characterization of the cellular and antitumor effects of MPI-0479605, a smallmolecule inhibitor of the mitotic kinase Mps1. Mol Cancer Ther. 2011;10:2267-75.

31. Liu Y, Lang Y, Patel NK, Ng G, Laufer R, Li SW, Edwards L, Forrest B, Sampson PB, Feher M, et al. The Discovery of Orally Bioavailable Tyrosine Threonine Kinase (TTK) Inhibitors: 3-(4- 
(heterocyclyl)phenyl)-1 H-indazole-5-carboxamides as Anticancer Agents. J Med Chem. 2015;58:3366-92.

32. Naud S, Westwood IM, Faisal A, Sheldrake P, Bavetsias V, Atrash B, Cheung KM, Liu M, Hayes A, Schmitt J, et al. Structure-based design of orally bioavailable $1 \mathrm{H}$-pyrrolo[3,2-c]pyridine inhibitors of mitotic kinase monopolar spindle 1 (MPS1). J Med Chem. 2013;56:10045-65.

\section{Figures}
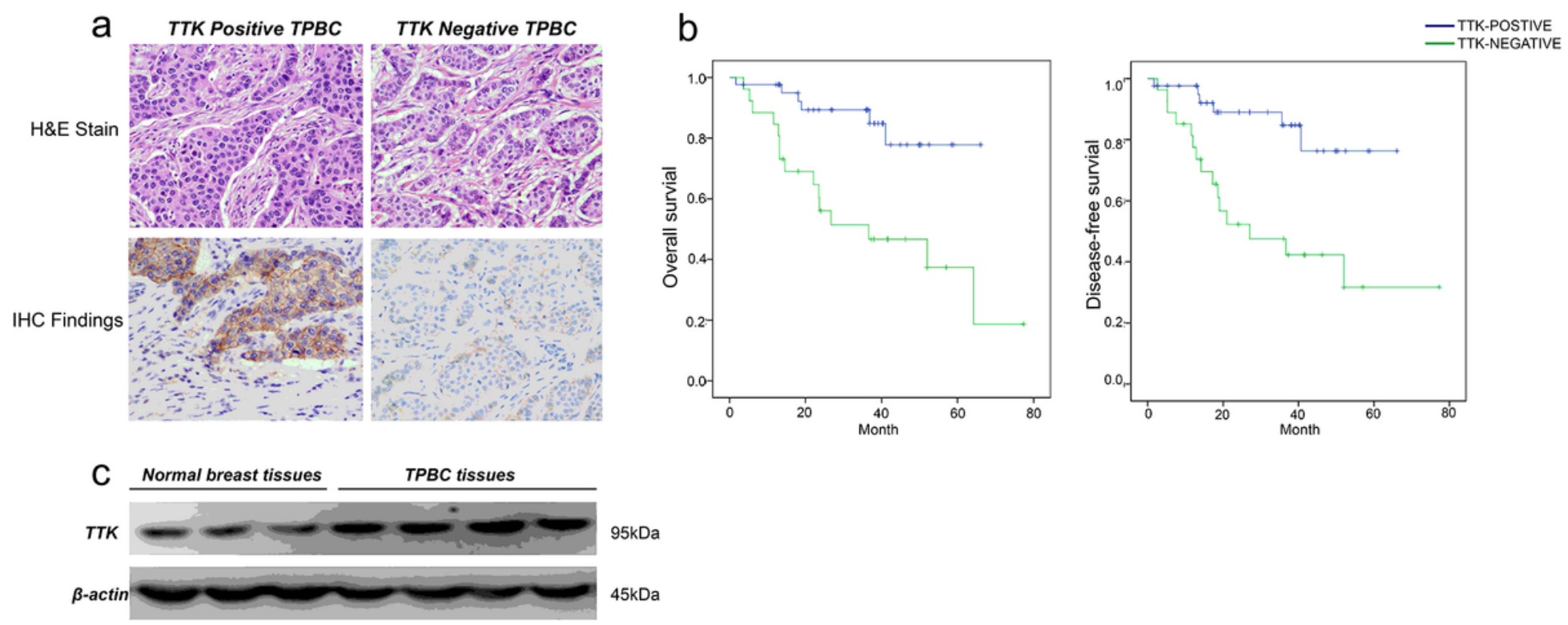

\section{Figure 1}

TTK expression in triple positive breast cancer (TPBC) tissues; (a) Positive and negative expression of TTK in breast cancer tissues (original magnification $\times 100$ ); (b) Higher TTK expression can predict shorter disease-free survival and overall survival of TPBC patients $(P=0.001$ and $P=0.050)$; (c) TTK protein expression in normal breast tissues and TPBC tissues was detected via western blotting. 

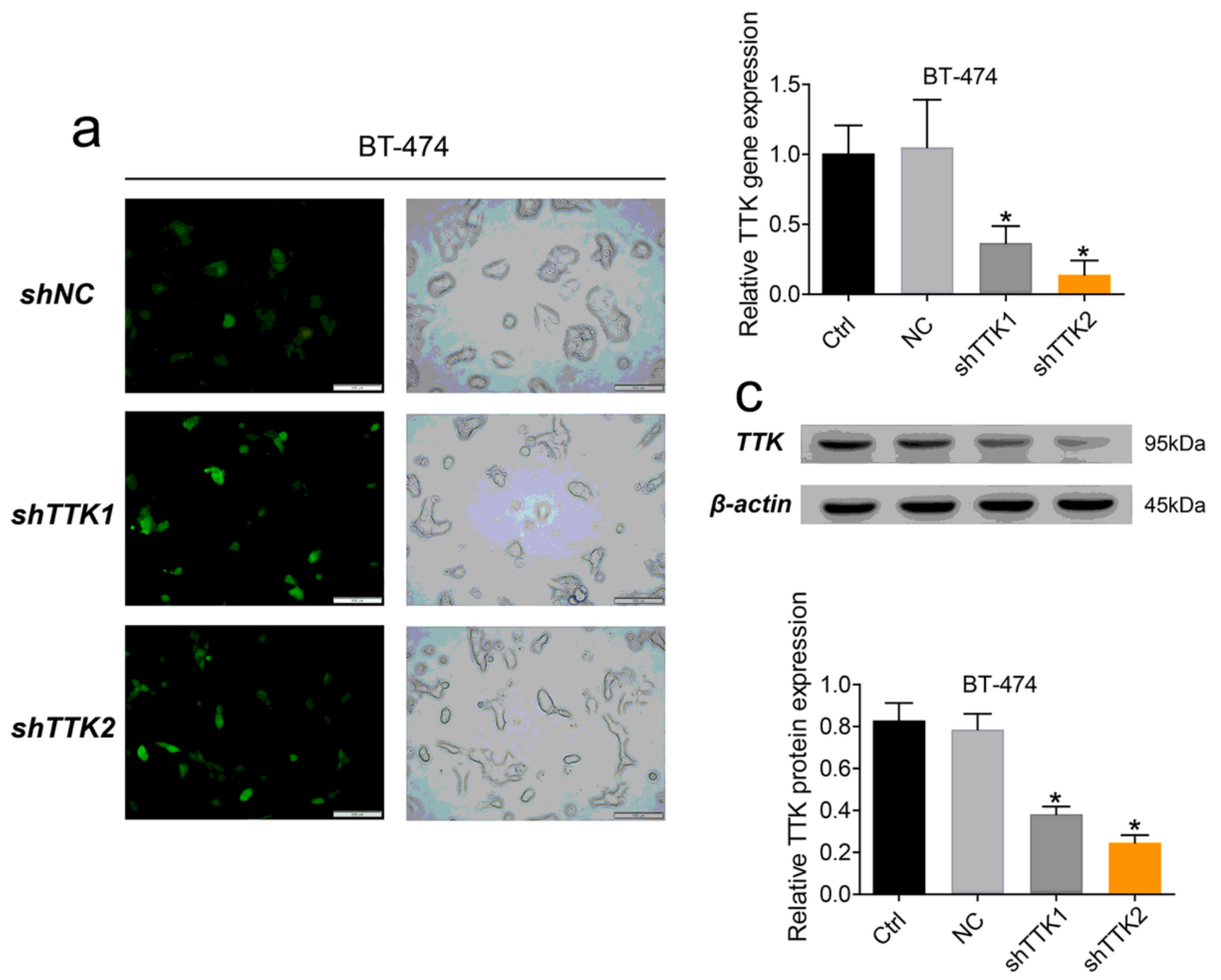

Figure 2

TTK knockdown. (a) Green fluorescent protein expression in BT474-TS cells detected by confocal microscopy; (b) mRNA levels of TTK in BT474-TS cells detected by RT-PCR; (c) TTK protein expression in BT474-TS cells detected by western blotting. Data are presented as mean \pm SD. The data shown are representative results of three independent experiments. ${ }^{*} P<0.05$. 


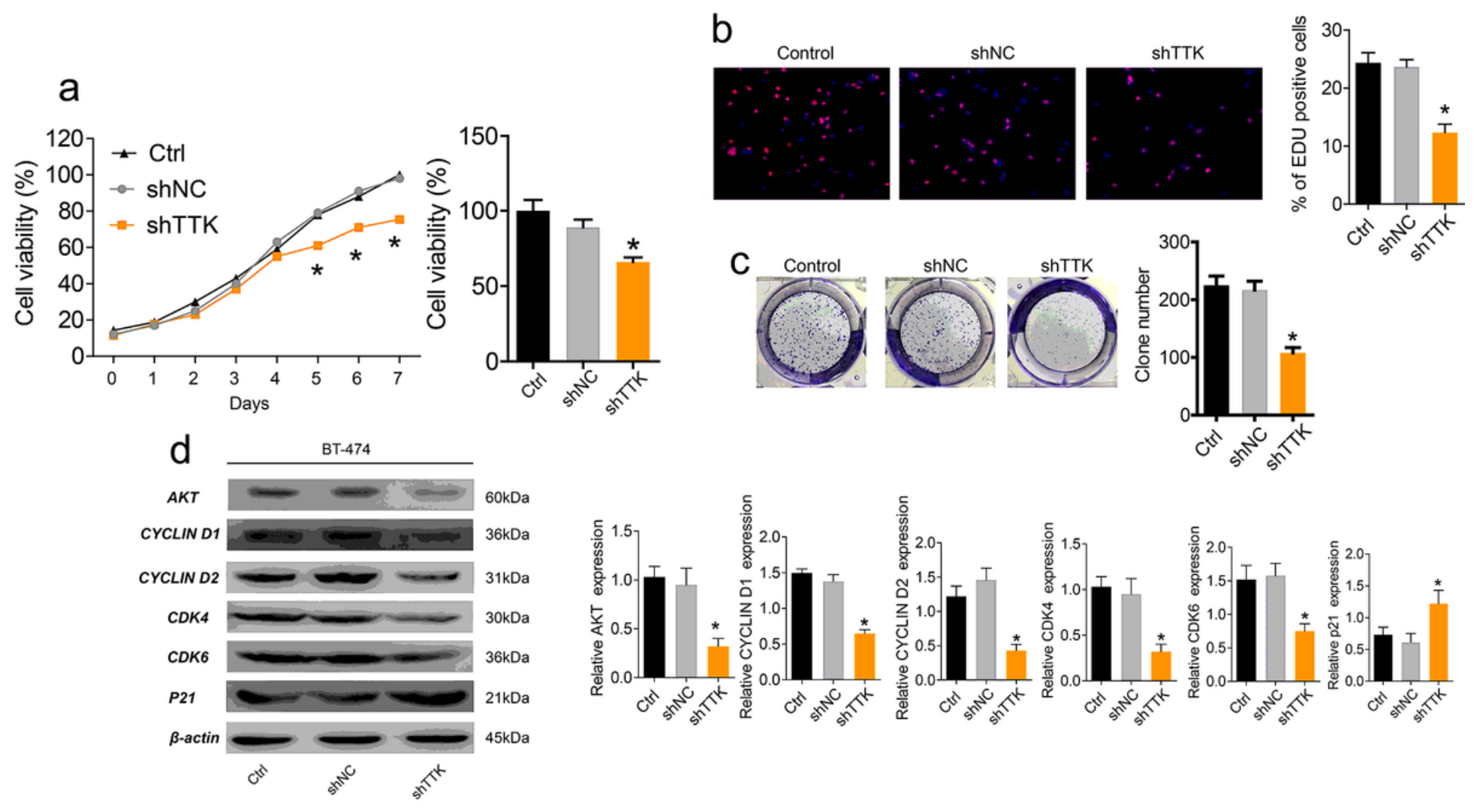

Figure 3

TTK knockdown inhibits proliferation of TPBC cells. (a) CCK-8 assay detected the effects of TTK knockdown on BT474-TS cell proliferation; (b) EdU assay detected the proliferation of TTK-knockdown and control group cells (magnification $\times 40$ ); (c) Colony formation assay was performed to detect the number of clones formed by TTK-knockdown and control group cells (magnification $\times 20$ ); (d) Western blot analysis of proliferation-related protein expression. Data are presented as mean \pm SD. The data shown are representative results of three independent experiments. ${ }^{*} P<0.05$. 


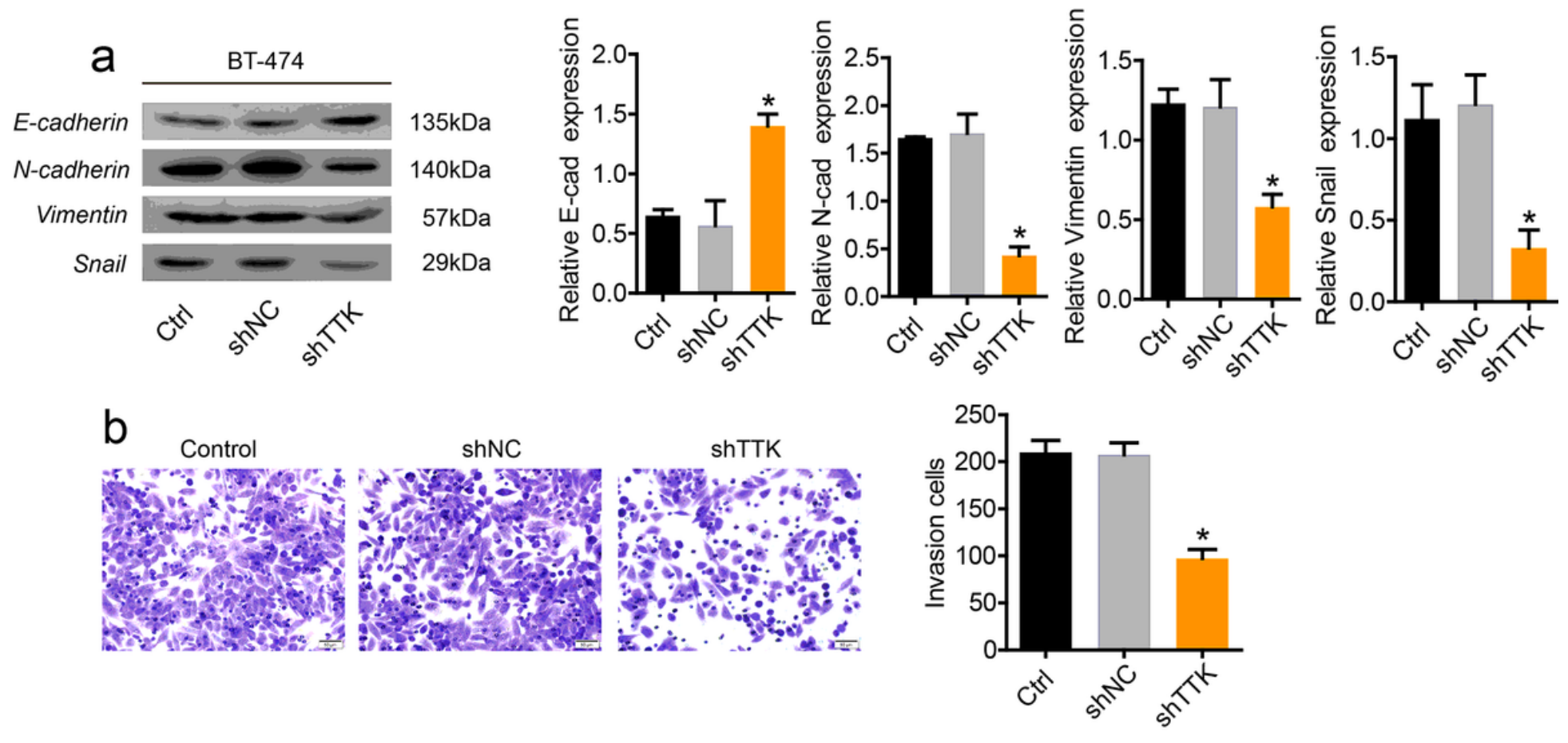

Figure 4

TTK knockdown inhibits invasion by TPBC cells. (a) Western blot analysis of EMT-related protein expression; (b) Transwell assay of migration and invasion by TPBC cells. Data are presented as mean \pm SD. The data shown are representative results of three independent experiments. ${ }^{*} P<0.05$.
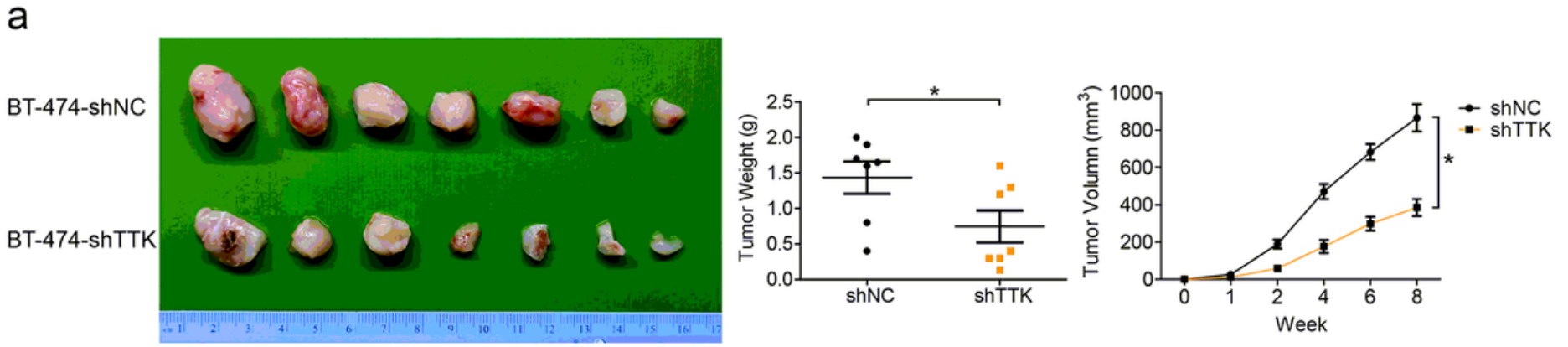

b

BT-474-shTTK
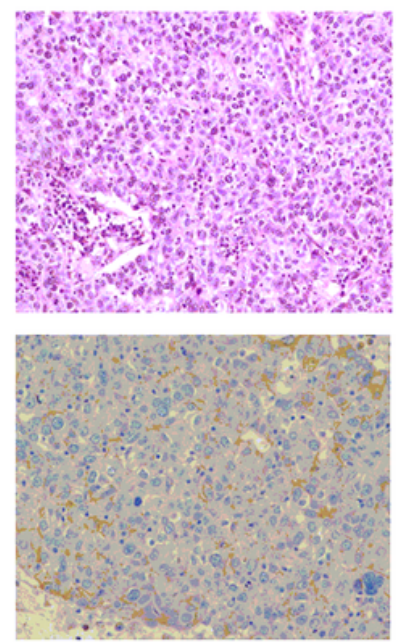

BT-474-shNC
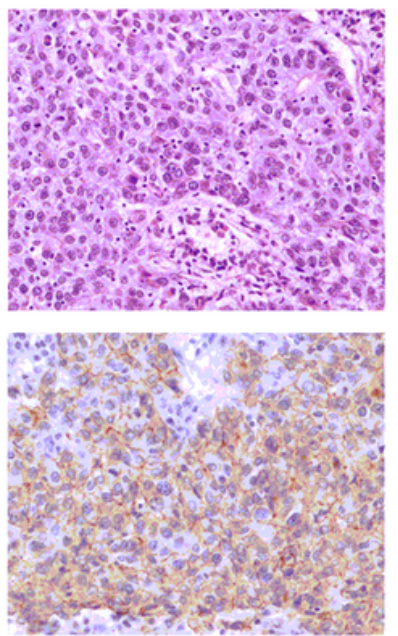

C

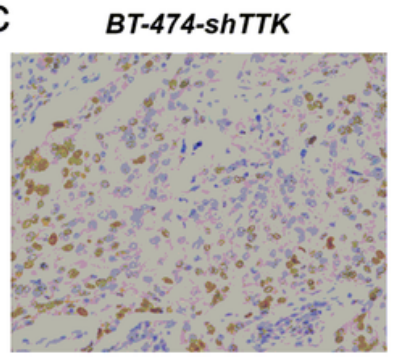

Ki67 status

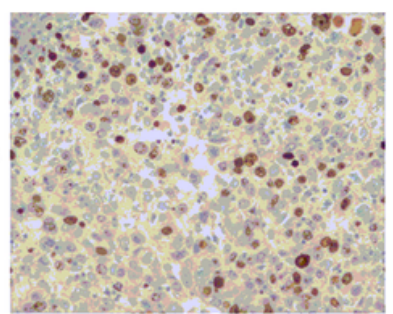

BT-474-shNC
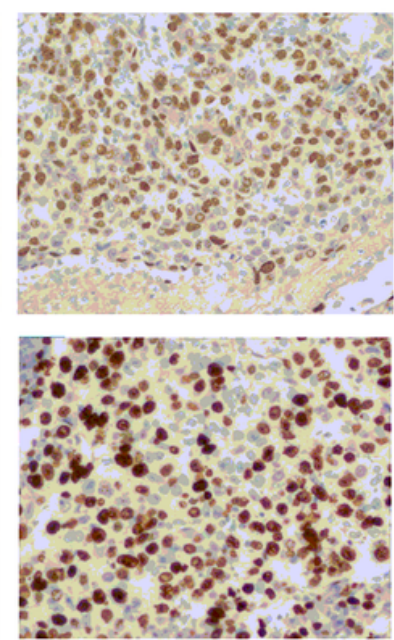


\section{Figure 5}

TTK knockdown inhibits the growth of TPBC cells in vivo. (a) Tumor xenograft weights and volumes of the TTK-knockdown and control groups; (b) TTK, AKT, and Ki-67 index expression was lower in the TTKknockdown and control groups than in the TTK-expressing group, as revealed by IHC of mouse tumor xenografts (original magnification $\times 100$ ). Data are presented as mean $\pm \mathrm{SD}$. The data shown are representative results of three independent experiments. ${ }^{*} P<0.05$. 